\title{
Assessing Enterprise Governance of Information Technology Maturity Models in Middle East and North Africa Region
}

\author{
Mostafa M. AlShamy, Walid M. Abdelmoez, \\ Essam Eldean Elfakharany \\ College of Computing and Information Technology, \\ Arab Academy for Science, Technology and Maritime Transport, Egypt \\ Email: mostafa.alshamy@egybyte.net, walid.abdelmoez@aast.edu, \\ essam.elfakharany@aast.edu
}

\author{
Hany H. Ammar \\ Lane Department of Computer \\ Science and Electrical Engineering, \\ West Virginia University, WV, USA \\ Email: hammar@wvu.edu
}

\begin{abstract}
Enterprise Governance of IT (EGIT) is an important topic for academics and practitioners in the context of achieving enterprise goals while optimizing resource utilization and risk management. EGIT is playing a critical role in developing countries as resources are rare and risk levels are higher. There is a need for EGIT Maturity Models (MMs) in Middle East and North Africa (MENA) region detected by delivering and analyzing two questionnaires which were shared with a group of participants working in the field. The obtained results have been generalized and consolidated into a generally applicable requirement list covering the specific needs of MENA region. The results of this paper reveal that although there are some global EGIT MMs used in MENA region which cover some maturity dimensions, there is a lack of easy-to-use integrated multi-dimensional EGIT MMs specific for the region needs.
\end{abstract}

\section{INTRODUCTION}

$\mathrm{M}$ ATURITY Models (MMs) are techniques developed and used to determine the level of performance, capability or maturity of process or organization [1]. They are used to discover organizations strength and weakness points to enable them to define respective opportunities for improvement. They are also used to determine maturity targets and how to reach them. We tried to get Middle East and North Africa (MENA) region respective stakeholders involved by developing and sharing two questionnaires to know more about how their organizations select, use, and integrate Enterprise Governance of IT (EGIT) MMs. The analysis of these two questionnaires revealed a demand in the MENA region for having an EGIT MM with special characteristics covering the local needs and context.

MENA region has some specific needs based on the nature of its member countries as they all are developing countries with emerging economies based on the natural and human resources they have and great opportunities for improvement. At the same time, the Arab Peninsula countries are emerging with their eagerness to achieve great improvements over short times due to their new economic strategies which include many dimensions include information technology, cybersecurity, and data management among others. The region is starting to believe in the importance of corporate governance and EGIT in achieving the national and organizational goals and objectives effectively. Many counties like Egypt, Kingdom of Saudi Arabia (KSA), United Arab Emirates (UAE) among others begin to have strategic vision for 2030 and many respective initiatives with clear goals, roles and responsibilities and actual measurement techniques.

Organizations in MENA region are becoming more interested in EGIT as we discovered that around $80 \%$ of organizations are trying to implement or have already implemented an EGIT MM based on the conducted questionnaires. Those organizations need a MM that can enable them to measure their EGIT maturity and guide them to improve their performance to achieve their goals and comply with emerging regulations while optimizing resources and risk. None of MMs examined in this research uses stage-based and multi-dimensional maturity measurement methodology as they are just using separate dimensions and maturity levels except for COBIT 2019 [2] which uses different dimensions but does not have stage-based maturity measurement methodology. Therefore, these MMs enforce the interested organizations to use more than one of them together. At the same time, to measure all respective processes/aspects of the organization against each maturity level is specially considered huge effort for small and medium organizations. Therefore, many organizations cannot implement EGIT measurement and improvement easily due to the lack of a single easily integrated MM. We could not find any information about any EGIT $\mathrm{MM}$ which was developed in or for the MENA region to cover its context and maturity level. Therefore, we will assess the MMs in MENA region and define the needs of its organizations.

In this paper we present the result of assessing EGIT MMs in the MENA region and the specific needs of organizations working in it which are interested in measuring and improving their EGIT maturity. It should be noted that EGIT here has governance stands for Governance, Risk and Compliance (GRC) combined. We aim to define the needs of the organizations working in the MENA region to know if there is a need for a new EGIT MM, or the existing MMs are effective and efficient. If a new EGIT MM is needed, we target to identify its characteristics to guide researchers who may be interested in developing one. The objective is to design questionnaires to cover EGIT management and usage 
and provide them to respective representatives from some organizations working in different fields and representing different sized organizations. Their answers will be analyzed properly. This will lead us to know the MENA region EGIT MM needs and customization.

This paper is organized as the following. Section 2 covers the literature review. Section 3 covers assessing organizations using EGIT MM in the MENA. Section 4 covers conclusions and future work.

While maturity itself is defined by Rosemann and de Bruin [3] as "a measure to evaluate the capabilities of an organisation in regard to a certain discipline", Becker et al [1] define MM as "conceptual models that outline anticipated, typical, logical, and desired evolution paths towards maturity". They are also used to determine maturity targets and how to reach them. MMs can have three purposes [3]:

- Descriptive which measures the current state (AS-IS) of an entity,

- Prescriptive which determines the desired state (TOBE) of an entity and

- Comparative which allows entities to benchmark.

Descriptive MMs measures the current existing maturity levels in organization against predefined maturity levels to enable organizations to know their actual achievements. This enables organizations to understand their capabilities and weaknesses based on neutral assessment and analysis techniques.

Prescriptive MMs enable organizations to determine which future maturity level suites their goals and objectives that can be achievable too. They help organizations in defining maturity targets to follow by initiating improvement initiatives and assign needed competent resources.

Comparative MMs enable different organizations to compare their maturity achievements in a benchmark style. It is a great type of MMs, but it needs many arrangements to guarantee its effectiveness and efficiency. It enables organizations to rank their maturity in a specific market or field. Participating organizations must accept to share specific information with other entities including the other participating organizations to enable the MM to measure the actual maturity level and there shall be an external neutral assessor to manage the whole process professionally.

\section{II.LITERATURE REVIEW}

There are more than $150 \mathrm{MMs}$ developed and published in the last few years as stated by de Bruin et al. [3] to support IT management. and in a research conducted by Becker et al [1] they found more than one thousand academic articles probably dealing with MMs published during the period of 1994 to 2009 when they applied a maturity model keyword search in ten scientific databases. When they tried to extend their analysis in 19 pure IS journals their search resulted in 20 articles that focus on MM. They discovered that there is no clear guidance on how to develop a MM using a scientific methodology. Becker's procedure model [4] is considered the greatest source of guidance for developing any EGIT MM due to the simple and scientific eight requirements provided.

We conducted a search for Maturity Model and IT Governance Maturity Model key words in three major publishers indexed in Scopus with good Cite Score which are IEEE, Springer Nature and Elsevier. The search covered MM in two geographical locations which are worldwide and MENA region. The result of the search is depicted in Table 1. There are no IT Governance MMs in the MENA region based on IEEE and Elsevier while there is a few found on Springer Nature. After examining those found on Springer Nature, we found them not related to IT Governance by any means.

The existent MMs are belonging to one of two different approaches, the first one of them is the commercial approach which is based on the efforts of big service providers and bodies of knowledge. The other approach is the academic one with many researchers who attempted to develop MMs while they do not have enough resources and capabilities like the first approach. This part will cover the existent MMs and compare among them.

Although there are many existing MMs in the field of information and technology, all of them lack one or more needed EGIT dimensions and some of them are not targeting EGIT. There is a need to assess the existing MMs from the organizations and stakeholders' perspectives. Therefore, we developed and shared two questionnaires to collect and analyze stakeholders' feedback to have general overview of the current situation of EGIT MMs in the MENA region. The need for a new MM with specific characteristics which suite more organizations in the region has be detected.

\section{A. Maturity Models Classification}

The first approach which is commercial EGIT MMs will be covered here by three of the most famous maturity/capability models in the market and two ISO

TABLE 1

MM AND IT GOVERNANCE MM IN LEADING SCIENTIFIC JOURNALS.

Search Keyword

MM

IT Governance MM
IEEE

$\begin{array}{cc}\text { Worldwide } & \text { MENA } \\ 3,165 & \text { N/A } \\ 86 & \text { N/A }\end{array}$

Elsevier

$\begin{array}{cc}\text { Worldwide } & \text { MENA } \\ 27,452 & \text { N/A } \\ 340 & \text { N/A }\end{array}$

Springer Nature

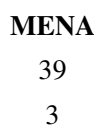


standard which many companies were trying to use to know their maturity level and how to improve it. IT Infrastructure Library (ITIL) framework [5] is considered the most famous public framework for IT Service Management (ITSM) for the last thirty years and it has so many practitioners in the MENA who have attended its training courses and took certification exams. It has a lifecycle for any IT service which includes five stages empowered by twenty-six processes, four main IT functions and many techniques for managing IT services and increasing the customer satisfaction in a measurable manner. ITIL v3 and its 2011 update included a MM called Process Maturity Framework (PMF) [5] which is an easy-to-use multi-purpose ITSM MM that measures the maturity of ITSM processes using five maturity levels from 1 to 5 which are called initial; repeatable; Defined; Managed and Optimizing. Each level measures five areas which are considered dimensions and they are Vision and steering; Process; People; Technology and Culture. It is an ITSM MM while it can be used to measure any other domain. It assesses all the processes against each maturity level.

Control Objectives for Information and Related Technology (COBIT 5) [6] was considered the most famous public framework for Governance of Enterprise Information and Related Technology from 2012 to 2018 when it was replaced by COBIT 2019, and it has a Process Capability Model [7]. It has many practitioners in the MENA who have attended its training courses and took certification exams. It differentiated between governance and management and the processes of each. It was created based on other best practices which are governance principles from ISO/IEC 38500 [8], risk management from ISO 31000 [9], enterprise architecture from TOGAF [10], project management methodology from PRINCE2 [11] and PMBOK [12], information security management from ISO/IEC 27001 [13], application capability measurement from CMMI [14], IT service management processes from ITIL 2011 [4] and ISO/IEC 20000 [15]. COBIT5 has thirty-two management processes in four domains and five governance processes in one domain. COBIT5 has capability model called Process Capability Model which is built on the internationally recognized ISO/IEC 15504-2 standard [16] for Software Engineering - Process Assessment standard. ISACA which is the owner and developer of COBIT5 refuses to use the term maturity as it assumed that maturity can be used for measuring many dimensions of an organization and not only one as COBIT5 which was just measuring processes, so it will be reasonable to use capability instead of maturity. It measures the capability of IT governance and management processes using six capability levels from 0 to 5 which are Incomplete Process; Performed Process; Managed Process; Established Process; Predictable Process and Optimising Process. Each capability level has four ratings which are Fully (> $85 \%$ to $100 \%$ achievement), Largely (> $50 \%$ to $85 \%$ achievement), Partially (> $15 \%$ to $50 \%$ achievement) and Not achieved (0 to $15 \%$ achievement). It has nine attributes within the second to the sixth capability levels. The attributes found in a specific capability level shall be fully achieved so that the assessment can go for the next level. It is not an easy-to-use multi-purpose EGIT MM for MENA as many organizations do not have many of its processes and do not have enough resources to conduct its complex assessment. COBIT5 has only one dimension which is Process and therefore it measures capability and not maturity, other dimensions are still needed like information security, business continuity and compliance. It assesses all the processes against each maturity level and a simpler version tailored for the needs of MENA region is needed to cover its specific needs.

COBIT 2019 [2] is the new version of COBIT5 which was released by ISACA at the end of 2018. Now it has more processes as it has 35 processes for IT Service Management and 5 processes for Governance. It is not an easy-to-use multi-purpose EGIT MM [17]. It uses CMMI® Development 2.0 [14] process capability scheme. It has four dimensions which are Process, Organizational Structures, Information Items and Culture and Behavior. It has the same six maturity levels and four ratings like COBIT5. It is not easy to be used as it has six maturity levels including nine attributes and four ratings per each. It needs training, experience, and more resources to be implemented. It covers four dimensions, and therefore it measures capability for each dimension and maturity for all of them combined. It covers ITSM, information security, continuity, and compliance as processes and not as dimensions. It assesses all the processes against each maturity level.

ISO/IEC 15504-2 [16] is a guidance ISO standard created for process improvement and process capability determination. It is not an easy-to-use multi-purpose process MM. It has only one dimension which is Process. It has six capability levels which are Incomplete, Performed, Managed, Established, Predictable and Optimizing. It has nine attributes covering the second to the sixth capability levels. It is dedicated to process measurement and provided an exemplar software life cycle process assessment model. It is not easy to be used in MENA region due to its complexity and resource consuming style. It needs training and experience to be implemented. It covers one dimension, which is process, and therefore it measures capability and not maturity, other dimensions are still needed. It assesses all the processes against each maturity level.

ISO 19600 [18] is a guidance ISO standard published in 2014 and was created to provide organizations with guidance on how to comply with regulations and avoid fines by having a compliance management system. It is not a MM nor provides a maturity measurement like the other MMs mentioned above. Like many ISO standards it can measure compliance to its requirements by having one of two states which are conformity or non-conformity. It has only one dimension which is compliance which was missing in all the other mentioned MMs except for COBIT. It could be easy to be used in MENA region due to its straightforward requirements and maturity measurement technique and the increasing number of emerging regulations in the region. It covers one dimension and therefore other dimensions are 
still needed. It was replaced by ISO 37301 [19] which was released in 2021.

For MENA region, ITIL is considered the best one for ITSM while COBIT is considered the best one for EGIT. But they still need to be customized to cover MENA region specific requirements.

The second approach covers relevant academic governance of IT maturity/capability models that represent researchers' participation which does not reach to proper audience in many cases. Although, de Bruin stated that there are more than $150 \mathrm{MMs}$ in the last few years, the related work here represents the most related MMs or their development guidance. The related works can be divided into three categories which are the first category proposing MMs, the second category comparing among the developed MMs and the third category providing guidance on how to develop a scientific MM.

GoCoMM: A Governance and Compliance Maturity Model [17] by G. Gheorghe et al, Toward an IT Governance Maturity self-assessment Model Using EFQM and CobiT [20] by S. Arezki et al, Maturity Model Architect A Tool for Maturity Assessment Support [21] by Diogo Proença et al, Using Enterprise Architecture Model Analysis and Description Logics for Maturity Assessment [22] by D. Proença et al, Software process improvement and capability determination [23] by A. Mas et al and An Overview of the Business Process Maturity Model (BPMM) [24] by Jihyun Lee et al, are representing the first category which propose MMs. All these researchers tried to develop and propose a MM related to one aspect or more of EGIT.

Comparing among the developed MMs which is the second category is represented by MATURITY MODELS IN IS RESEARCH [1] by J. Becker et al, The Maturity Models for Information Systems - A State of the Art [25] by D. Proença et al and Understanding maturity models Results of a Structured Content Analysis [26] by Kohlegger, M., Maier, R., \& Thalmann, S. The researchers are comparing among a group of proposed and released MMs and trying to discover their respective shortcomings.

Providing guidance on how to develop a scientific MM which is the third category is represented by Information Governance Maturity Model - Final Development Iteration [27] by Proença et al, What makes a useful maturity model? a framework of general design principles for maturity models and its demonstration in business process management [28] by J. Pöppelbuß et al, Maturity assessment models: a design science research approach [29] by $T$. Mettler et al and Developing Maturity Models for IT Management - A Procedure Model and its Application [30] by J. Becker et al, Assessing Organizational Capabilities: Reviewing and Guiding the Development of Maturity Grids [31] by Anja M. Maier et al, What Makes A Useful Maturity Model? A Framework Of General Design Principles For Maturity Models And Its Demonstration In Business Process Management [32] by Jens Pöppelbuß and Maximilian Röglinger, IT Evaluation in Business Groups: A Maturity Model [33] by Hamel, F., Ph, T., Falk, H., \& Walter, U, Understanding the Main Phases of Developing a Maturity Assessment Model, (December) [34] by Bruin, T. De, Freeze, R., \& Rosemann, M and A Design Science Research Perspective on Maturity Models in Information Systems [35] by Mettler, T. In this category researchers tried to provide other researchers who are interested in developing MMs with guidance on how to develop and evaluate MMs properly.

Although the first category which proposes new MMs and the second category which compares among the already developed MMs are important, the last category which is providing guidance on how to develop a MM is very important as we will use its provided guidance in understanding how to develop a scientific MM if needed for the MENA region. The following Table 2 gives a summary of the covered dimensions of the MMs used in the market

TABLE 2.

MM COMPONENTS COVERED BY EXISTING MMS AND ISO STANDARDS.

\begin{tabular}{|c|c|c|c|c|c|c|c|}
\hline References & ITSM & $\begin{array}{c}\text { Information } \\
\text { Security }\end{array}$ & $\begin{array}{c}\text { Business } \\
\text { Continuity }\end{array}$ & Compliance & Process & People & Technology \\
\hline ITIL PMF & $*$ & $*$ & $*$ & & $*$ & $*$ & $*$ \\
\hline COBIT 5/2019 & $*$ & $*$ & $*$ & $*$ & $*$ & $*$ & $*$ \\
\hline ISO/IEC 15504-2 & & & & & $*$ & & \\
\hline \multicolumn{8}{|l|}{ M_o_R MM } \\
\hline \multicolumn{8}{|l|}{ P3M3 MM } \\
\hline ISO/IEC 20000-1:2018 & * & * & * & & * & * & \\
\hline ISO/IEC 27001:2013 & & $*$ & $*$ & & $*$ & $*$ & $*$ \\
\hline ISO 2230-1:2019 & & & $*$ & & $*$ & $*$ & $*$ \\
\hline ISO 19600:2014/37301:2021 & & & & $*$ & $*$ & $*$ & \\
\hline GoCoMM & & & & & $*$ & & \\
\hline $\begin{array}{l}\text { Toward an IT Governance Maturity } \\
\text { self-assessment Model Using } \\
\text { EFQM and CobiT }\end{array}$ & & & & & * & & \\
\hline $\begin{array}{l}\text { Maturity Model Architect A Tool } \\
\text { for Maturity Assessment Support } \\
\end{array}$ & & & & & * & & \\
\hline $\begin{array}{l}\text { Using Enterprise Architecture } \\
\text { Model Analysis and Description } \\
\text { Logics for Maturity Assessment }\end{array}$ & & & & & * & & \\
\hline $\begin{array}{l}\text { A Formalization of the ISO/IEC } \\
15504 \text { Enabling Automatic } \\
\text { Inference of Capability Levels }\end{array}$ & & & & & $*$ & & \\
\hline
\end{tabular}


TABLE 3.

EXISTING MMS AND ISO STANDARDS FEATURES AND MAIN AREAS OF APPLICATION IN ORGANIZATIONS.

\begin{tabular}{|l|c|c|c|c|}
\hline \multirow{2}{*}{ References } & \multicolumn{3}{|c|}{ Features } & $\begin{array}{c}\text { Main Areas of } \\
\text { Application }\end{array}$ \\
\cline { 2 - 5 } & Public/Proprietary & Easy to use & $\begin{array}{c}\text { Descriptive (D)/ } \\
\text { prescriptive (P)/ } \\
\text { comparative (C) }\end{array}$ & ITSM \\
\hline ITIL PMF & Public & Yes & (D)/(P)/(C) & EGIT \\
\hline COBIT 5/2019 & Public & No & (D)/(P)/(C) $/(\mathrm{P}) /(\mathrm{C})$ & Process Measurement \\
\hline ISO/IEC 15504-2 & Public & No & (D)/(P)/(C) & Risk Management \\
\hline M_O_R MM & Public & Yes & (D)/(P)/(C) & $\begin{array}{c}\text { Portfolio, Program, and } \\
\text { Project Management } \\
\text { Maturity Model }\end{array}$ \\
\hline P3M3 MM & Public & Yes & (D)/(P)/(C) & ITSM \\
\hline ISO/IEC 20000-1:2018 & & & (D)/(P)/(C) & Information Security \\
\hline ISO/IEC 27001:2013 & Public & Yes & (D)/(P)/(C) & Business Continuity \\
\hline ISO 2230-1:2019 & Public & Yes & (D)/(P)/(C) & $\begin{array}{c}\text { Compliance } \\
\text { Management }\end{array}$ \\
\hline ISO 19600:2014/37301:2021 & Public & Yes & Yes & \\
\end{tabular}

whether they are commercial or academic to depict the differences among them. It will start with the commercial MMs and then the academic MMs. No MM covers all EGIT dimensions with stage-based maturity levels.

Table 3 covers the most famous MMs used currently in the market and all of them are not academic ones. It compares among these MMs based on their features and main areas of application in organizations. The features show whether they are public or proprietary, ease of use and whether they are descriptive, prescriptive, or comparative.

\section{B. MENA Region Evaluation}

We searched Elsevier, IEEE and Springer Nature for MENA EGIT MM and we could not find any MMs which were developed in MENA region or specially developed for it. Although we have many EGIT MMs and regulations developed out of MENA region and used worldwide, we can find only regulations developed and enforced in the MENA region. These regulations are like Saudi National Cybersecurity Authority (NCA) cybersecurity controls and SAMA business continuity management and cybersecurity frameworks in the Kingdom of Saudi Arabia or the Egyptian Personal Information Protection Act among others. We could not find any EGIT MMs developed in or for MENA region that care about its context and special needs.

\section{ASSESSING ORGANIZATIONS USING EGIT MM IN THE MENA REGION}

The study aims to understand the existing EGIT MMs in the MENA region which should enable organizations to improve their enterprise governance of IT in an easy and affordable manner while helping them to comply with emerging regulations. The quantitative approach is used in this research by developing and distributing two questionnaires, which were developed and published using
Google Docs, to 118 participants who are working in EGIT and related functions including IT, Information Security, GRC, QA, Business Analysis, IT Service Management, IT Project Management, Infrastructure, IT Networks, IT Operations, Performance Management and Audit. The first questionnaire [36], which was published in 2019, asks the participants about their organizations' behavior regarding EGIT using eighteen questions while the second one [37], which was published after a few months in 2020, asks them about their organizations' behavior towards EGIT and regulations using thirty questions. The number of participants in the first questionnaire is eighty-three and the number of the second questionnaire participants is thirty-five and they provided valuable feedback which enriched our research with market needs. The first questionnaire is dedicated to EGIT MMs while the second one is concentrating on compliance MMs in addition to EGIT MMs. The number of participants in the second questionnaire is less than of those of the first one as the number of those who are interested in compliance is less than the number of those who are generally interested in EGIT. The participants of the two questionnaires are working in micro, small, medium, and large enterprises operating in Egypt, Saudi Arabia, UAE, Sudan, Jordan, Yemen, among other countries in MENA.

The main objective of these two questionnaires is to define how organizations in the MENA region manage the EGIT maturity measurement using MMs. Both are structured questionnaires with a group of sequence questions leading the participants to describe how their organizations measure their EGIT maturity levels by using MMs. They start with asking the participants about their organizations type, size, location, and sector in addition to the position of participants. Then, a group of multiple-choice questions is provided to participants with the ability to choose one or more options that match their environment. 
The two questionnaires were trying to get answers for questions like:

- Whether organizations define and internally publish their strategies, goals, applicable regulations, and the implications of not complying with them?

- Whether organizations define their EGIT goals and map them to applicable regulations with respective annual improvement initiatives and how to measure their achievements?

- Whether organizations measure the maturity of their EGIT and how?

- Whether organizations use one or more MMs to measure the maturity of their EGIT and for which purpose (Comparative, Prescriptive and Comparative)?

- The ease of use of the used MMs and cost of implementation in addition to the need for professional training?

- Whether the used MMs are scientifically developed, and which dimensions are included?

- The first-, second- and third-party assessments applicability of the used MMs and the type of assessors?

- The preferred EGIT MM dimensions and language?

- The need for one integrated MM or different ones to measure organizations' EGIT maturity and compliance to respective regulations?

The results gained after analyzing the answers of participants confirmed our point of view that MENA region needs an easy-to-use integrated multi-dimensional EGIT MM that suites the specific context of the region.

Table 4 gives a small set of the most important preferences of users of the MMs that depict the characteristics of the MMs used in MENA market based on the answers of the first questionnaire participants. It is clear that some of the participants' organizations just measure the achievement of goals and objectives instead of using market well-known MMs. About third of the participants confirmed that they use more than one MM while half of participants stated that the used MMs are developed using a scientific methodology and are easy to be used. More than half of the participants confirmed that they use MMs for descriptive, prescriptive, or comparative purposes, while a higher percentage of participants stated that they need training to implement these MMs. Some of the participants stated that their MMs are expensive. Few participants stated that their MMs are easy to

TABLE 4.

CHARACTERISTICS AND TYPES OF MMS IN MENA REGION BASED ON $1^{\text {ST }}$ QUESTIONNAIRE.

\begin{tabular}{ll}
\multicolumn{1}{c}{ Aspect } & Percentage \\
$\begin{array}{l}\text { Organizations use market well known } \\
\text { MMs }\end{array}$ & 23.5 \\
$\begin{array}{l}\text { Organizations just measure } \\
\text { goals/objectives }\end{array}$ & 28.4 \\
Organizations use more than one MM & 37.3 \\
Scientifically developed MMs & 50.8 \\
Easy to use MMs & 47.5 \\
MMs that need training for implementation & 78 \\
Expensive MMs & 35.6
\end{tabular}

be used for a self-assessment.

These statistics show that MENA market needs to have a scientifically developed EGIT MM that integrates other market well-known MMs while having descriptive, prescriptive, and comparative purposes. It should be easy-tounderstand and easy-to-use. If the MM will be publicly free, it will increase the number of its users and specially the organizations which do not have enough resources. The analysis of the first questionnaire also depicts the needs of MENA market for all types of MMs and if there is one MM covering First, Second and Third-party assessments it will cover different segments of organizations. Self-assessment and easy-to-use capabilities are also needed to enable small organization to measure their EGIT too.

Table 5 gives a summary of the dimensions of the MMs used in MENA region based on the answers of the first questionnaire participants. Not less than half of the participants confirmed that their organizations have one or more of the measured dimensions in their used EGIT MMs. Based on their use, the dimensions are ordered in a descending manner from Process, Technology, Risk, Projects, Programs, and Portfolio, collectively, Compliance, Management Commitment to People.

All the provided percentages show big demand for all these EGIT dimensions in MENA region, and it will be great having them combined in just one integrated MM.

Table 6 gives a summary of the preferences of the users of the existing MMs in MENA market based on the answers of the second questionnaire participants. A high percentage of participants stated that their organizations need to use MM for measuring EGIT and compliance and more than half of participants preferred to use one integrated MM instead of using many MMs in addition to the ability of having internal and external assessors. This means that there is a big need for an integrated EGIT MM which can be used by internal and external assessors.

Based on the analysis of the second questionnaire, Table 6 gives a summary of how the organizations started to define applicable regulations and measure their compliance. A high percentage of organizations define applicable regulations and the implications of not complying with them and map their goals to applicable regulations. Measuring compliance

TABLE 5 .

DiMENSIONS OF MMS IN THE MENA REGION BASED ON $1^{\text {ST }}$ QUESTIONNAIRE.

\begin{tabular}{lc}
\multicolumn{1}{c}{ Aspect } & Percentage \\
Management commitment & 50.8 \\
Process & 72.9 \\
People & 50.8 \\
Technology & 71.2 \\
Risk & 59.3 \\
Projects, programs, and portfolio & 55.9 \\
Compliance & 55.9
\end{tabular}


TABLE 6.

PREFERENCES OF USERS OF MMS IN THE MENA REGION BASED ON $2^{\mathrm{ND}}$ QUESTIONNAIRE.

\section{Aspect}

Organizations need to use EGIT MM

Organizations prefer to use one integrated MM

Organizations prefer internal and external assessors

Organizations need compliance MM

Defined applicable regulations and the implications

of non-compliance

Organizations map their goals to applicable regulations

Internal auditors measure compliance to respective regulations

External auditors measure compliance to respective regulations

Organizations prefer Arabic/English MM

Organizations prefer English MM

Organizations prefer Arabic MM
Percentage

79.8

57.1

63.1

77.1

74.3

40

42.8

51.4

37.1

11.4 with respective regulations by internal and external auditors is almost equal.

For language preference, the highest percentage is for Arabic/English MM, then English alone and the least percentage is for Arabic alone. It should be noted that all Arab Gulf Region countries have a high percentage of foreign labor who do not speak Arabic and their second language is English. The International Labour Organization (ILO) stated on its 2021 published Global Estimates on International Migrant Workers report [38] that the Arab States are considered the third highest sub-region hosting the majority of international migrant workers with $14.3 \%$ after Northern, Southern and Western Europe with $24.2 \%$ and Northern America with 22.1\%.

The current increase in the IT and Personal Indefinable Information (PII) regulations worldwide and in MENA region affects the EGIT in all organizations which do not like to breach these regulations and have many risks like losing reputation, having to pay huge fines and penalties or legal implications.

After analyzing the results of the conducted two questionnaires we discovered that there is a great need in the MENA region for an EGIT MM that suites the characteristics of the region. These statistics can be used in the future to develop a customized EGIT MM for the MENA region.

\section{CONCLUSIONS AND FUTURE WORK}

MMs importance is increasing every day due to the increasing dependance in our world on IT services and their respective regulations. There are many IT and EGIT MMs in the market which were developed globally. At the beginning there was a belief that there is a demand for measuring EGIT maturity in MENA region organizations due to the increase of EGIT awareness level and the increase in emerging cybersecurity and PII regulations. A literature review was conducted leading us to know that there is a lack of scientifically developed EGIT MMs worldwide and that famous MMs are concentrating on limited number of dimensions to measure. Two dedicated questionnaires were developed and shared with 118 participants who are working in EGIT and related functions in MENA region to understand if the currently used EGIT MMs are effective and efficient or there is a need to develop other MMs.

Based on the literature review, our published two questionnaires and the analysis of the answers of the participated individuals, we found that many organizations use worldwide known best practices frameworks and standards to measure their EGIT maturity. Based on $57.1 \%$ of participating individuals, there is a need to develop an integrated MM for measuring the EGIT that suites the MENA region specific context instead of using more than one MM. An inexpensive, easy-to-use, and scientifically developed multi-purpose, multi-dimensional and stage-based maturity levels MM is needed to cover organizations' needs.

The results of this paper can provide guidance to other researchers who are interested in developing EGIT MM for developing countries and especially those in MENA region. Those researchers can use this guidance in developing our recommended research topics:

- Develop MMs and all their components to enable organizations to use them for assessing their EGIT maturity with the capability of multi-purpose, multi-dimension and stage-based maturity levels maturity assessment.

- Develop guidance for those who would like to be assessors on how to develop their knowledge about any newly developed MM, what are the needed skills and how to use the developed MMs.

- Choose some of the interested organizations and support them in implementing the developed MMs to check the validity of the developed MMs and how organizations can accept the idea of having just one multi-dimensional stagebased MM.

- Develop awareness program and gain participating organizations top management commitment from the beginning to make all stakeholders comply and reduce change resistance as much as possible.

\section{REFERENCES}

[1] Becker, Joerg; Niehaves, Bjoern; Poeppelbuss, Jens; and Simons, Alexander (2010), "Maturity Models in IS Research". ECIS 2010 Proceedings. Paper 42.

[2] ISACA, COBIT® 2019 FRAMEWORK: INTRODUCTION \& METHODOLOGY, (2018).

[3] de Bruin, Tonia \& Rosemann, Michael. (2005). Towards a Business Process Management Maturity Model. Proceedings of the 13th European Conference on Information Systems. 521-532.

[4] J. Becker, R. Knackstedt, and J. Pöppelbuß, (2009) "Developing Maturity Models for IT Management,” Bus. Inf. Syst. Eng., vol. 1, no. 3, pp. 213-222

[5] AXELOS ITIL Homepage, https://www.axelos.com/best-practicesolutions/itil. Accessed 20/7/20.

[6] Office of Government Commerce, Service Design, UK, TSO (2007), pp. 263. 
[7] ISACA, A Business Framework for the Governance and Management of Enterprise IT (2012).

[8] ISO organization, ISO-IEC 38500:2008 Corporate governance of information technology.

[9] ISO organization, ISO 31000:2009 Risk management — Principles and guidelines.

[10] Open Group Homepage, https://www.opengroup.org/togaf. Accessed 20/7/20.

[11] AXELOS PRINCE2 Homepage, https://www.axelos.com/bestpractice-solutions/prince2. Accessed 20/7/20.

[12] PMI PMBOK Homepage, https://www.pmi.org/pmbok-guidestandards. Accessed 20/7/20

[13] ISO organization, ISO-IEC 27001:2013 Information technology Security techniques - Information security management systems Requirements.

[14] CMMIINSTITUTE Homepage, https://cmmiinstitute.com. Accessed $20 / 7 / 20$

[15] ISO organization, ISO-IEC 20000-1:2018 Information technology Service management -

[16] ISO organization, ISO-IEC 15504-2:2003 Information technology Process assessment - Part 2- Performing an assessment.

[17] G. Gheorghe, F. Massacci, and A. Pretschner, (2009) "GoCoMM: A Governance and Compliance Maturity Model $*$," pp. 33-37.

[18] ISO organization, ISO 19600:2014 Compliance management systems - Guidelines.

[19] ISO organization, ISO 37301:2021 Compliance management systems - Requirements with guidance for use.

[20] S. Arezki and Y. Elhissi, (2018) "Toward an IT governance maturity self-assessment model using EFQM and CobiT," Proc. Int. Conf. Geoinformatics Data Anal. - ICGDA '18, pp. 198-202.

[21] Diogo Proença and José Borbinha, (2018) "Maturity Model Architect: A Tool for Maturity Assessment Support" - 10.1109/CBI.2018.10045

[22] D. Proença and J. Borbinha, (2018) "Using enterprise architecture model analysis and description logics for maturity assessment," Proc. 33rd Annu. ACM Symp. Appl. Comput. - SAC '18, no. November, pp. 102-109.

[23] A. Mas and A. Mesquida, (2018) "Software process improvement and capability determination conference 2017," Comput. Stand. Interfaces, vol. 60 , no. November 2018, pp. 1-2.

[24] Lee, J., Lee, D., \& Kang, S. (2007). An Overview of the Business Process Maturity Model (BPMM) BT - Advances in Web and Network Technologies, and Information Management. In K. C.-C. Chang, W. Wang, L. Chen, C. A. Ellis, C.-H. Hsu, A. C. Tsoi, \& H. Wang (Eds.) (pp. 384-395). Berlin, Heidelberg: Springer Berlin Heidelberg.
[25] D. Proença and J. Borbinha, (2016) "Maturity Models for Information Systems - A State of the Art," Procedia Comput. Sci., vol. 100, no. December, pp. 1042-1049.

[26] Kohlegger, M., Maier, R., \& Thalmann, S. (2009). Understanding maturity models Results of a Structured Content Analysis, (December 2016).

[27] Proença, Diogo \& Vieira, Ricardo \& Borbinha, José. (2017). Information Governance Maturity Model Final Development Iteration. 128-139. 10.1007/978-3-319-67008-9 11.

[28] J. Pöppelbuß and M. Röglinger, (2011) "What makes a useful maturity model? A framework of general design principles for maturity models and its demonstration in business process management," Proc. IEEE Int. Eng. Management Conf., no. August 2014, pp. 244-249.

[29] T. Mettler, (2011) "Maturity assessment models: a design science research approach," Int. J. Soc. Syst. Sci., vol. 3, no. 1/2, p. 81.

[30] J. Becker, R. Knackstedt, and J. Pöppelbuß, (2009) "Developing Maturity Models for IT Management,” Bus. Inf. Syst. Eng., vol. 1, no. 3, pp. 213-222.

[31] Maier, A. M., Moultrie, J., \& Clarkson, P. J. (2012). Assessing Organizational Capabilities: Reviewing and Guiding the Development of Maturity Grids.

[32] Poeppelbuss, J., \& Roeglinger, M. (2011). What makes a useful maturity model? A framework of general design principles for maturity models and its demonstration in business process management

[33] Hamel, F., Ph, T., Falk, H., \& Walter, U. (2013). IT Evaluation in Business Groups: A Maturity Model.

[34] Bruin, T. De, Freeze, R., \& Rosemann, M. (2005). Understanding the Main Phases of Developing a Maturity Assessment Model, (December).

[35] Mettler, T. (2009). A Design Science Research Perspective on Maturity Models in Information Systems.

[36] M. Alshamy, (2019) "Multi-Purpose and Dimension Enterprise Governance of IT (EGIT) Maturity Model (MM). Internet: https://docs.google.com/forms/d/e/1FAIpQLSf0ForiyeJ46qVeew5MY dynYAedwIaRXXyjGpk63SJmUfaRZg/viewform?usp=sf link

[37] M. Alshamy, (2020) "Multi-Purpose and Multi-Dimension Enterprise Governance of IT (EGIT) Maturity Model (MM) for MEA. Internet: https://docs.google.com/forms/d/e/1FAIpQLSe8p_ZmTl13wQo6gFrH yDHfqE9o0JYViZ86luosWq8csHSnIA/viewform?usp=sf_link.

[38] ILO Global Estimates on International Migrant Workers, https://www.ilo.org/wcmsp5/groups/public/---ed protect/---protrav/--migrant/documents/publication/wcms_808946.pdf. Accessed 16/7/21. 